\title{
OUTLET ROUX-Y-GASTRIC BYPASS POUCH REDUCTION USING ARGON PLASMA COAGULATION TO TREAT WEIGHT REGAIN: A Randomized Controlled Trial with SHAM Group
}

Dr. Idiberto Jose Zotarelli Filho, MSc, Ph.D ${ }^{1}$

${ }^{1}$ Affiliation not available

January 4, 2021

\begin{abstract}
Aims: This study to evaluate the efficacy and complications of Argon Plasma Coagulation (APC) therapy to treat post-RYGB weight regain compared to a sham control group. Methods: 41 Patients with minimum regain of $10 \mathrm{~kg}$ and minimal postoperative time of 36 months was randomized into two groups. Results: In the APC group $(\mathrm{n}=21)$, the mean initial weight $100.4 \mathrm{~kg}$, and mean regained weight of $24.94 \mathrm{~kg}$. In the Sham group $(\mathrm{n}=20)$, the mean initial weight of $103.65 \mathrm{~kg}$, and mean regained weight of $25.18 \mathrm{~kg}$. Only happened anastomosis stenosis after the first APC session. The comparative results between the APC versus the Sham were percentage recovered weight loss (63.95 x-2.65), weight loss in $\mathrm{kg}(15.02 \mathrm{x}-0.57)$, percentage total weight loss (14.46 $\mathrm{x}-0.62), \%$ excess weight loss $(54.32 \mathrm{x}-2.34)$, and BMI reduction $(5.38 \mathrm{x}-0.21)$, with a $\mathrm{p}<0.0001$ for all the comparisons. There was a significant reduction in the APC group of HbA1c $(5.66 \%$ to $4.96 \%)$ and triglycerides $(153.20 \mathrm{mg} / \mathrm{dL}$ to $132.20 \mathrm{mg} / \mathrm{dL})$. Conclusion: This study proves that APC outlet pouch reduction is much superior compared to sham in promoting weight loss for patients that presented weight regain after de RYGB.
\end{abstract}

Ricardo José Fittipaldi-Fernandez ${ }^{1}$, Anna Carolina Hoff², Idiberto José Zotarelli-Filho ${ }^{3,4^{*}}$, Marcelo Falcão de Santana $^{5,6}$, João Henrique Felicio de Lima ${ }^{7}$, Fernando Santos Silva Bastos ${ }^{5,6}$, Newton Teixeira dos Santos ${ }^{8}$

1. EndogastroRio Clinic, Rio de Janeiro/RJ, Brazil.

2. Angioskope Clinic, Endoscopy, Sao Jose dos Campos/SP, Brazil.

3. FACERES - Faculty of Medicine of Sao Jose do Rio Preto/SP, Brazil.

4. Zotarelli-Filho Scientific Work, Sao Jose do Rio Preto/SP, Brazil.

5. IFEC-Instituto Falcão de Endoscopia e Cirurgia (Falcão Institute of Endoscopy and Surgery), Salvador/BA, Brazil.

6. EBMSP-Escola Bahiana de Medicina e Saúde Pública (Bahiana School of Medicine and Public Health), Salvador/BA, Brazil.

7. Endobatel-Digestive endoscopy, Universidade Federal do Paraná-UFPR (Federal University of Paraná), Curitiba/PR, Brazil.

8. NT Santos Serviços médicos (NT Santos-Medical services), Rio de Janeiro/RJ, Brazil. 


\section{INTRODUCTION}

Obesity represents a serious emerging disease with consequent negative public health outcomes. ${ }^{[1]}$ There are currently more than 2.0 billion overweight and obese people in the world, and Brazil is in fifth place in the world ranking, with an estimate of more than 18.0 million people. ${ }^{[2]}$

In this scenario, bariatric surgery is more effective in weight loss and control of comorbidities in relation to dietary procedures and drugs. ${ }^{[3]}$ Despite the good results and control of the disease in the medium and long term, the Roux-en-Y Gastric Bypass (RYGB) features about $20 \%$ of the patients submitted to this surgery do not lose the desired weight in the first year or regain weight after 18 to 24 months. ${ }^{[3]}$ The weight regains process can involve several variables, highlighting the size of the gastric pouch (GP), size of the gastrojejunal anastomosis (GJA), BMI prior to surgery, eating habits, psychiatric disorders, problems with self-esteem and socioeconomic conditions. ${ }^{[4,5]}$

According to the International Federation for the Surgery of Obesity and Metabolic Disorders (IFSO) in its report published in 2015, about 86 thousand bariatric surgeries were performed in Brazil, $70.0 \%$ of which was RYGB -type laparoscopic gastroplasty. ${ }^{[6]}$ In this sense, several studies regarding RYGB have shown significant results, including increasing survival, reducing cardiovascular mortality, and controlling metabolic diseases. ${ }^{[7-9]}$

In this context, the most common late complication is the recurrence of obesity, in which the main associated factors are food error and bad lifestyle habits associated with a sedentary lifestyle, which can cause an increased gastric reservoir and dilation of the diameter of the GJA and among others. ${ }^{[10,11]}$ Thus, GJA above $15.0 \mathrm{~mm}$ has been associated with obesity recurrence, especially when associated with complaints of decreased satiety or early hunger due to rapid gastric emptying. ${ }^{[11-13]}$

In this sense, the narrowing of the dilated GJA through argon plasma coagulation (APC) in the recurrence of obesity, in patients undergoing RYGB, presents itself as an effective and safe alternative, according to important published works. ${ }^{[14-18]}$ As a consequence of weight gain after RYGB, abnormal anatomical findings are found in $71.2 \%$ of patients, with $58.9 \%$ presenting with GJA dilation. ${ }^{[18]}$ Therefore, APC is technically feasible and reproducible, relatively inexpensive, and with numerous advantages over the usual electrocoagulation. ${ }^{[14-17]}$ The complications have a low incidence and the tissue penetration limit of 2.0 to $3.0 \mathrm{~mm}$ associated with adequate coagulation allows its application in critical areas such as the duodenum and the colon. ${ }^{[18]}$

Thus, decreasing the diameter of a dilated anastomosis can lead to a $23 \%$ reduction in excess weight on average, together with the monitoring of a multidisciplinary team. ${ }^{[18]}$ In this sense, the recurrence of obesity is associated with decreased quality of life and recurrence of comorbidities. ${ }^{[19,20]}$

Thus, the present study assessed the efficacy and complications of APC therapy in treating post- RYGB weight recovery compared to a sham control group.

\section{MATERIALS AND METHODS}

\section{Trial Design}

A prospective randomized study that included 41 patients out of 132 submitted to eligibility analysis. All selected patients completed the follow-up, with no exclusion during the study period. The clinical research rules-CONSORT (Available at http://www.consort-statement.org/) were used.

\section{Sample Size}

The sample size has estimated at a total of 41 participants for further randomization into two groups. Specifically, a standard deviation of 18.5 has hypothesized for the change in weight after the APC procedure based on previous studies as well as a $95 \%$ CI confidence interval and a $5 \%$ dropout rate of patients. ${ }^{[18,21]}$ 


\section{Ethical Considerations}

The study has reviewed and approved by the Clinical Institutional Review Board and has conducted in accordance with the ethical standards laid out in the 1964 Declaration of Helsinki and its later amendments or comparable ethical standards. Informed consent has obtained from all individual participants included in the study.

\section{Participants}

Inclusion criteria were patients who underwent RYGB surgery, with a minimum recovery of $10 \mathrm{~kg}$ and a minimum postoperative time of 36 months, loss of feeling full, bag size between 4.0 and $7.0 \mathrm{~cm}$, diameter $<5.0 \mathrm{~cm}$ and gastrojejunal anastomosis $>15.0 \mathrm{~mm}$. Exclusion criteria were another type of surgery or normal stomach, lack of consent, eating sweets, taking anticoagulant drugs, alcoholism, depression, and compulsive disorders.

Three APC sessions were held, with an 8-week interval between them. Patients' weight has assessed at the beginning of treatment and 2, 4, and 6 months later. Both groups received standard nutritional guidance immediately after each APC session or upper digestive endoscopy. Both groups received a liquid diet.

\section{Randomization}

The random sequence has generated using the Minitab $18^{\circledR}$ statistical program (version 18, Minitab, LLC, State College, Pennsylvania, USA) by a researcher not involved in the allocation of participants. Block randomization has used without stratification and has implemented by an administrative assistant using sequential numbering, sealed envelopes. Individuals in the argon arm underwent three APC sessions, with an 8-week interval between them. The endoscopic evaluation has performed every 2 months until completing 6 months. In the control group, the arm underwent an initial diagnostic endoscopy followed by clinical consultation every 2 months until the sixth month. All patients were blinded to the intervention they received. The multidisciplinary team (nutritionist, psychologist, and physical educator) and data analysts were also blinded to the allocation of participants.

\section{Groups}

\section{Group I (APC)}

Patients who underwent APC therapy performed around the gastrojejunal anastomosis in a $2.0 \mathrm{~cm}$ halo. This group underwent multidisciplinary monitoring, through consultations with a bariatric surgeon, psychologist, physical educator, and nutritionist. The returns were made every 2 months until completing 6 months.

\section{Group II (SHAM)}

Patients who underwent only upper digestive endoscopy with sedation. This group also did the multidisciplinary follow-up, through consultations with a bariatric surgeon, psychologist, physical educator, and nutritionist. The returns were made every 2 months until completing 6 months.

\section{Setting}

All endoscopic procedures, APC sessions, and data collection took place at the EndogastroRio Clinic, Rio de Janeiro-RJ, Brazil and Angioskope Clinic, São José dos Campos-SP. The recruitment of participants started in May 2019, with the end of the monitoring taking place in December 2019.

\section{OUTCOMES}

\section{Primary outcomes}

Weight loss recurred at 2, 4, and 6 months more significantly compared to the control group. The following parameters will be evaluated: weight loss in $\mathrm{Kg}$, reduction of the body mass index (BMI), percentage loss of recovered weight (\% RWL), percent Total body weight loss (\% TWL), and percent EWL (\% EWL).

\section{Secondary outcomes}


Incidence of adverse events such as bleeding and strictures, improvement of laboratory metabolic parameters (Glycosylated hemoglobin (HbA1c), total cholesterol, LDL, HDL triglycerides) and improvement in the eating behavior.

\section{INTERVENTIONS}

\section{APC Application and Exams}

Argon has approved by the National Health Surveillance Agency (ANVISA) in Brazil and is low-cost. All examinations were performed with a minimum fasting of 8 hours, and the patient was in the left lateral position, with instillation of $10.0 \%$ xylocaine spray, followed by intravenous propofol under the supervision of an assistant physician (anesthesiologist) with adequate cardiopulmonary monitoring throughout the period examination using a Pentax EG-2970K endoscope (Pentax, Tokyo, Japan). To measure the gastrojejunal anastomosis, a graduated rule has used every $5.0 \mathrm{~mm}$ developed from a catheter for endovascular surgery laser. The images obtained were transferred to a Pentax EPK-1000 processor coupled to a computational unit, containing the ZScan 7 program (Goiânia, GO/Brazil). Then, an argon plasma (Argon 2-WEM, Ribeirão Preto, SP) has applied, with a disposable endoscopic catheter and applied over the entire circumference of the gastrojejunal anastomosis, forming a $2 \mathrm{~cm}$ thick halo, using a power of $90 \mathrm{~W}$ and flow of $2.5 \mathrm{~L} / \mathrm{min}$.

After procedure and anesthetic recovery, all patients were released in the presence of a companion. Proton pump inhibitor Dexlansoprazole $60 \mathrm{mg}$ per day for up to 90 days after the last session and sucralfate $2 \mathrm{~g}$ of 12/12h for 10 days were prescribed. All patients received guidance and maintained contact with a physician in the face of adverse events. All patients were on a liquid diet for 10 days after each team return.

\section{Anthropometric and Laboratory Data}

The data for each registered patient was weight loss $(\mathrm{kg})$, measured using a calibrated digital scale, body mass index (BMI), and height and weight measurements were recorded twice at each visit to increase accuracy and reliability); bag size, measured using the graduation endoscope in relation to length (all bags that allowed the device to be retrovisioned were considered wide).

All outcome variables, except blood tests (total plasma cholesterol, high density lipoprotein cholesterol (HDL) and $\mathrm{HbA1c}$ ) were determined at randomization and in the second, fourth and sixth months after randomization.

Statistical analysis

The statistical analysis of the data has performed by an external collaborator (Dr. Idiberto José Zotarelli Filho) and interpreted by the principal investigator (Dr. Ricardo Fittipaldi-Fernandez). For data analysis, a database has built on the Microsoft Excel spreadsheet which has exported to the Minitab $18^{\circledR}$ statistical program (version 18, Minitab, LLC, State College, Pennsylvania, USA) (Minitabß) ${ }^{[22]}$ and OriginPro @ 9 (DPR Group, Inc., Northampton, Massachusetts, USA). ${ }^{[23]}$ A common descriptive statistical analysis has performed, obtaining the values of total "n", mean and standard deviation, confidence interval (CI), and percentage for all the variables. Normality test has performed for all variables. One-Way test (ANOVA) has applied, adopting the $\alpha$-level less than 0.05 with a statistical difference for $95 \%$ CI. The R-sq $\left(\mathrm{R}^{2}\right)$ value has also analyzed.

\section{RESULTS}

A total of 41 patients were randomized into 2 groups, the APC and Sham group, with each group having 21 and 20 patients respectively. The flowchart of selection and eligibility, as well as the randomization process of the patients selected in their respective APC and Sham groups, after applying the inclusion and exclusion criteria, is shown in Figure 1. In the APC group (4 men), age mean was 46.65 years, mean initial weight of 100.4 (range of 72-162) kg, mean initial BMI of $36.12 \mathrm{~kg} / \mathrm{m}^{2}$ and mean weight recovered of 24.94 (range of 15 to 82 ). In the Sham group ( 7 men), the mean age was 49.53 years, the mean initial weight was 103.65 (range: $88.70-123.70) \mathrm{kg}$, the mean baseline BMI was $36.67 \mathrm{~kg} / \mathrm{m}^{2}$ and the average recovered weight 25.18 (range: 19.50-32.30) Kg. 
Only one complication occurred, stenosis after the first APC session, requiring no treatment since the patient tolerated a liquid diet, and remained in the study. The technique was $100 \%$ successful.

The overall results of both groups regarding relapsed weight loss, weight loss in $\mathrm{kg}$, total body weight loss (\% TBWL), excessive weight loss (\% EWL), reduced BMI, reduced serum triglyceride level and glycosylated hemoglobin are shown in Table 1. Figure 2 shows the weight reduction of the two groups over time. The APC group had an average initial weight of $100.04 \pm 22.27$ and, after 6 months, the average weight was $85.02 \pm$ $16.05 \mathrm{~kg}$, with $15.02 \pm 9.63 \mathrm{~kg}$ of weight reduction, thus, there was a statistically significant difference with p $<0.0001$ and $\mathrm{R}^{2}=45.34 \%$ (CI 95\%). The sham group did not present statistical difference regarding weight loss, with $\mathrm{p}>0.0001$ and $\mathrm{R}^{2}=99.85 \%$ (CI 95\%), with an average of initial and initial weight respectively equal to $103.65 \pm 10.53 \mathrm{~kg}$ and $104.22 \pm 10.06 \mathrm{~kg}$, with a weight gain of $0.57 \pm 2.23 \mathrm{~kg}$. There was also a significant difference between the APC and Sham groups in relation to the final weight results, with $\mathrm{p}$ $<0.0001$. BMI values in each group followed the same statistical results as weight values, as shown in Table 1 and Figure 3.

According to Figure 4, the values of \%RWL, percent Total body weight loss (\%TWL), and percent EWL (\%EWL) in relation to the APC group were $63.95+-32.08 \%, 14.46+-6.16 \%$, and $54.32+-28.90 \%$, respectively. Regarding the Sham group, they were respectively $-2.65+-10.24,-0.62+-2.43$, and $-2.34+-$ 9.03. The statistical comparison between groups was significant, with $\mathrm{p}<0.0001$.

The GJA diameter values in relation to the APC group were $34.25+-6.13 \mathrm{~mm}$ (initial), $12.65+-2.11 \mathrm{~mm}$ (final), with a reduction of $21.60+-3.19 \mathrm{~mm}$, with $\mathrm{p}<0.0001$ and $\mathrm{R}^{2}=35.43 \%$ (CI 95\%) . The sham group did not present statistical difference, with $\mathrm{p}>0.0001$ and $\mathrm{R}^{2}=99.99 \%$ (CI 95\%), with the same value of the initial and final anastomotic diameter equal to $35.16+-4.52 \mathrm{~mm}$ (Figure 5).

Several biochemical parameters were also analyzed. The mean values for total cholesterol, HDL and LDL before and after the SHAM group were $186.21+-25.36 \mathrm{mg} / \mathrm{dL}$ and $185.84+-24.27 \mathrm{mg} / \mathrm{dL}, 48.89+-11.26$ $\mathrm{mg} / \mathrm{dL}$ and $49.11+-10.16 \mathrm{mg} / \mathrm{dL}, 122.74+-25.36 \mathrm{mg} / \mathrm{dL}$ and $121.32+-27.36 \mathrm{mg} / \mathrm{dL}$, respectively, with $\mathrm{p}>0.0001$. In the APC group, these values were $187.25+-23.36 \mathrm{mg} / \mathrm{dL}$ and $186.50+-22.23 \mathrm{mg} / \mathrm{dL}, 48.40$ +- $8.26 \mathrm{mg} / \mathrm{dL}$ and $48.85+-8.18 \mathrm{mg} / \mathrm{dL}, 122.5+-24.34 \mathrm{mg} / \mathrm{dL}$ and $121.0+-25.14 \mathrm{mg} / \mathrm{dL}$, respectively, with $\mathrm{p}>0.0001$. The detainees in the reduction of the average values were in relation to the APC group in relation to HbA1c, with an initial average of $5.66+-0.61 \%$ versus the final average of $4.96+-0.39 \%$ $(\mathrm{p}<0.0001)$, and triglycerides with an initial mean of $153.20+-25.13 \mathrm{mg} / \mathrm{dL}$ versus the final average of $132.20+-31.46 \mathrm{mg} / \mathrm{dL}(\mathrm{p}<0.0001)$ (Figure 6).

There was a significant difference between the groups regarding the anastomotic diameter, with $\mathrm{p}<0.0001$. Figure 7 represents the GJA diameter images at 2, 4, and 6 months after the application of the APC.

\section{DISCUSSION}

The GJA review by APC is known to be a relatively safe and effective strategy to manage weight recovery after RYGB. Bleeding at the anastomotic site is an uncommon complication associated with this therapy. Another possible complication is the stenosis of the anastomosis. Endoscopic treatment is the first-line therapy for both situations ${ }^{[13]}$.

In the present study, the endoscopic APC has used with the objective of reducing the diameter of GJA and, therefore, promoting weight loss after RYGB that was relapsed. The results obtained were similar to the literature. Figures 2 and 3 show the results of weight loss in both groups, with the average weight reduction in the APC group being 15.02 +- 9.63 in relation to the Sham control group after 6 months. Thus, the present study confirms the literary findings, showing that this reduction in weight that has relapsed after RYGB is closely related to the reduction of the anastomotic diameter from $34.25+-6.13 \mathrm{~mm}$ (initial) to 12.65 +- $2.11 \mathrm{~mm}$ (final), with a reduction of $21.60+-3.19 \mathrm{~mm}$, considering that the liquid diet and nutritional counselling were applied in both groups.

Another important fact that the present study confirmed has in relation to the safety and efficacy of the APC outlet reduction procedure, given that there has only one complication due to stenosis after the first 
session of the APC, not requiring treatment. In addition, the technique has $100 \%$ successful.

According to the results of the present study, authors studied 30 patients undergoing treatment with an argon plasma, after gastric bypass, and observed after 3 endoscopic sessions of APC spaced between each other by 8 weeks, with an average weight loss of $15.0 \mathrm{~kg}$. In addition, a prospective controlled longitudinal study with APC showed a success rate of $90.0 \%$ for weight loss using APC and a reduction of up to $41.0 \%$ in the relapsed weight. ${ }^{[19]}$ Another study retrospective with 37 participants, the use of APC had a success rate of $50.0 \%$ for weight loss using $\mathrm{APC}$ and a $24.0 \%$ reduction in relapsed weight. ${ }^{[21]}$

Further, a study analyzed APC with a 3 and 6-month follow-up as anastomotic reduction therapy after RYGB and showed that in 53 patients (age $49.0+-1.3$ years, BMI mean was $52.1+-10.7 \mathrm{~kg} \mathrm{~m}^{-2}$. The postoperative period, BMI mean was $29.6+-1.1 \mathrm{~kg} \mathrm{~m}^{-2}$. The argon plasma has performed $8.6+-3.4$ years after RYGB, with weight recovery resulting in a BMI of $35.4+-1.1 \mathrm{~kg} \mathrm{~m}-2$. The reduction in anastomosis was $16.1+-3.7 \mathrm{~mm}$ to 13.5 . The average number of sessions was 1.3. ${ }^{[24]}$ An anastomotic diameter size over $15.0 \mathrm{~mm}$ in the weight regain scenario may be subject to endoscopic review. ${ }^{[18,32,33]}$

Also, authors published retrospective analysis data obtained from 558 patient records with regained weight in eight bariatric centers in the USA and Brazil, who underwent APC between July 31, 2009, and March 29, 2017. The mean weight was $94.5+-18.6 \mathrm{~kg}$ and the mean BMI was $34.0 \mathrm{~kg} / \mathrm{m}^{2}$ in the APC. When data were available, the mean of the lowest weight was $67.0+-23.0 \mathrm{~kg}$ and the mean of the lowest BMI was 24.1 $\mathrm{kg} / \mathrm{m}^{2}$ after RYGB. The average weight loss was $6.5,7.7$ and $8.3 \mathrm{~kg}$ at 6,12 , and 24 months, respectively, and the changes in weight over time were statistically significant. ${ }^{[11]}$

Besides, authors evaluated the efficacy and safety of endoscopic treatment of increased GJA with APC. A randomized controlled study was performed comparing APC to exclusive multidisciplinary management after regaining weight. Forty-two patients were divided into two groups: APC $(n=22)$ and control $(n=20)$. After 14 months of follow-up with a crossover in 6 months, significant improvement in satiety and greater weight loss has found in the APC group and after crossing. APC has associated with significant weight loss 9.73 vs. +1.38$)$, reduction in anastomosis diameter, early satiety ( 0.77 vs. 0.59$), \mathrm{p}<0.001$, and increased quality of life. Considering the average total weight loss during the entire follow-up, weight loss was similar in both groups (13.02 $\mathrm{kg}$ in the APC and $11.52 \mathrm{~kg}$ in the control). ${ }^{[12]}$

Also, another study published in $2020^{[14]}$, reported ablation with argon plasma coagulation (APC) plus full-thickness endoscopic suture (FTS-APC) and ablation alone for the treatment of weight recovery. A randomized, single-pilot study with forty patients, comparing the efficacy and safety of APC alone versus FTS-APC for transoral outlet reduction. Patients weighing at least $20 \%$ recover from the nadir and GJA [?] $15 \mathrm{~mm}$ were considered eligible. The primary endpoint was the percentage of total weight loss (\% TWL) in 12 months. Secondary outcomes were the incidence of adverse events, improvement in laboratory metabolic parameters and improvement in the quality of life, and eating behavior. At 12 months, the mean \%TWL was $8.3 \%+-5.5 \%$ in the APC group alone versus $7.5 \%+-7.7 \%$ in the STF-APC group. The percentage of solid pre-revision gastric retention in 1 hour was positively correlated with the probability of reaching [?] $10 \%$ TWL in 12 months. Both groups experienced significant reductions in levels of low-density lipoprotein and triglycerides at 12 months.

A recent retrospective study of two hundred and seventeen patients compared the effectiveness of different APC configurations in the treatment of weight recovery. Patients who received low-dose (45-55 W) and highdose $(70-80 \mathrm{~W})$ APC were compared. Of the selected patients, $116(53.5 \%)$ patients underwent low-dose APC sessions (2.4 sessions/patient) and 101 (46.5\%) patients underwent 144 APC sessions. in high doses (1.4 +- 0.7 sessions / patient). Follow-up rates were $82.9 \%$ and $75.3 \%$ at 6 and 12 months. At 6 months, the low and high dose groups showed $7.3 \%$ and $8.1 \%$ TWL, respectively. At 12 months, the low and high dose groups experienced $5.1 \%$ and $9.7 \%$ TWL, respectively. Technical success was $100 \%$. The overall rate of $\mathrm{AE}$ was $8.0 \%$, with stenosis being $4.6 \%$. Therefore, the higher watt APC has associated with greater weight loss. ${ }^{[15]}$

In this context, the authors Heneghan et al. $(2012)^{[25]}$ concluded that patients with normal post-surgical 
anatomy regain less weight than patients with altered proximal surgical anatomy, especially in the increase in the diameter of the gastrojejunal anastomosis. In addition, the authors $\mathrm{Abu}$ et al ${ }^{[26]}$ and Ramos et al. $(2017)^{[27]}$ evaluated the size of GJA and its influence on weight loss, where an anastomosis calibrated to 15.0 $\mathrm{mm}$ shows better results when compared to the anastomosis of $45.0 \mathrm{~mm}$ in a 2-year follow-up. Therefore, values between 10 and $15.0 \mathrm{~mm}$ are the desired GJA diameter.

Thus, several methods such as endoluminal reduction of GJA such as surgery ${ }^{[28]}$, suturing ${ }^{[29,30]}$, and APC in gastrojejunal anastomosis have been proposed to reduce the recovered weight in patients undergoing RYGB. ${ }^{[12]}$ In this scenario, surgical treatments are the most performed, however, they are associated with a higher incidence of complications and morbidity and mortality when compared to the other treatments proposed above. ${ }^{[28]}$

Besides, transoral outlet reduction (TORe) performed using a traditional suture pattern is effective in inducing short and medium-term weight loss in patients with weight recovery after RYGB. ${ }^{[30]}$ In this sense, a study analyzed the technical feasibility and safety of TORe in stock markets were determined and its impact on weight and metabolic profiles has assessed. Patients with RYGB who underwent pouch TORe were included. The GJA has ablated by coagulation with argon plasma or dissected by endoscopic submucosal dissection. A suture has used to place stitches around the GJA in a continuous ring. The suture has attached to a balloon $(8-12 \mathrm{~mm})$. The primary endpoint was technical feasibility. Secondary outcomes were the percentage of total body weight lost (\% TWL), adverse events, impact on comorbidities, and predictors of weight loss. Thus, 252 patients with RYGB were submitted to 260 TORe. They recovered $52.6+-46.4 \%$ of the weight lost and weighed $107.6+-24.6 \mathrm{~kg}$. The technical success rate was $100 \%$. At 6 and 12 months, the \% TWL was $9.6+-6.3$ and $8.4+-8.2$. At 12 months, blood pressure, hemoglobin A1c and ALT had improved. ${ }^{[31]}$

A systematic review and meta-analysis study evaluated the effectiveness of endoscopic therapies for recovered weight after RYGB. The primary endpoints were absolute weight loss (AWL), excess weight loss (EWL), and total body weight loss (TBWL). Thirty-two studies were included in the qualitative analysis. Twenty-six full-thickness (FT) endoscopic sutures described and AWL, EWL, and TBWL combined in 3 months were $8.5 \mathrm{~kg}, 21.6 \mathrm{~kg}$ and $7.3 \mathrm{~kg}$, respectively. At 6 months, they were $8.6 \mathrm{~kg}, 23.7 \mathrm{~kg}$ and $8.0 \mathrm{~kg}$, respectively. At 12 months, they were $7.63 \mathrm{~kg}, 16.9 \mathrm{~kg}$ and $6.6 \mathrm{~kg}$, respectively. Subgroup analysis showed that all results were significantly greater in the group with suture with TF combined with APC. Two articles described APC alone with an average AWL of $15.4+-2.0$ and $15.4+-9.1 \mathrm{~kg}$ at 3 and 6 months, respectively. When performing APC before the suture, it seems to result in greater weight loss. ${ }^{[32]}$

Since the loss of gastric restriction in the bypass can be one of the main causes of obesity recurrence. Therefore, the present study showed that the use of argon plasma in reducing the gastrojejunal anastomosis diameter promoted greater weight loss compared to the control group that underwent only to upper digestive endoscopy with sedation and liquid diet.

\section{CONFLICT OF INTEREST}

The authors declare they have no conflict of interest.

\section{INFORMED CONSENT}

Informed consent has obtained from all individual participants included in the study.

\section{ACKNOWLEDGMENTS}

We thank the strong support of Angioskope Clinic, Endoscopy, Sao Jose dos Campos/SP, Brazil, and the company Zotarelli-Filho Scientific Work, Sao Jose do Rio Preto/SP, Brazil.

\section{FUNDING}

Supported by EndogastroRio Clinic, Rio de Janeiro-RJ, Brazil.

\section{AUTHOR CONTRIBUTIONS}


(1) Conceptualization - Dr. Ricardo Jose Fittipaldi-Fernandez

(2) Data curation - Dr. Ricardo Jose Fittipaldi-Fernandez and Dra. Anna Carolina Hoff

(3) Formal analysis - Dr. Marcelo Falcao de Santana

(4) Funding acquisition - Dra. Anna Carolina Hoff

(5) Investigation - Dr. Joao Henrique Felicio de Lima

(6) Methodology - Dr. Joao Henrique Felicio de Lima

(7) Project administration - Dr. Ricardo Jose Fittipaldi-Fernandez

(8) Resources - Dr. Newton Teixeira dos Santos

(9) Software - Dr. Fernando Santos Silva Bastos

(10) Supervision - Dr. Idiberto Jose Zotarelli Filho

(11) Validation - Dr. Marcelo Falcao de Santana

(12) Visualization - Dr. Fernando Santos Silva Bastos

(13) Writing-original draft - Dr. Idiberto Jose Zotarelli Filho

(14) Writing-review\&editing - Dr. Newton Teixeira dos Santos

\section{DATA AVAILABILITY}

The authors declare that data supporting the findings of this study are available within the article.

\section{REFERENCES}

1. WHO- World Health Organization. Available in: https://www.sbcbm.org.br/endoscopia-e-obesidade/ Accessed June 20, 2020.

2. IBGE- Instituto Brasileiro de Geografia e Estatistica. Available in $<$ http://www.ibge.gov.br $>$. Accessed June 20, 2020.

3. Almby K, Edholm D. Anastomotic Strictures After Roux-en-Y Gastric Bypass: a Cohort Study from the Scandinavian Obesity Surgery Registry. Obes Surg. 2019 Jan; 29(1):172-177 [doi: 10.1007/s11695018-3500-9].

4. Keren D, Rainis T. Intragastric Balloons for Overweight Populations-1 Year Post Removal. Obes Surg. 2018. [doi: 10.1007/s11695-018-3167-2].

5. Falcao de Santana M, Menezes Marques L, Lopes Gibara V, E Magalhaes Neto G, Gustavo De Quadros L, Kaiser Junior RL, Gouvea Faria MA, Filho IZ. Ectopic spleen mimicking hepatocellular carcinoma in the late post-operative period of bariatric surgery. Cell Mol Biol (Noisy-le-grand). 2018, 30;64(13):113115 .

6. Docimo S Jr, Svestka M. Endoscopic Evaluation and Treatment of Postoperative Bariatric Surgery Complications. Surg Innov. 2017 Dec;24(6):616-624 [doi: 10.1177/1553350617736651. Epub 2017 Oct 26].

7. Schlosser T, Feisthammel J, Moessner J, Hoffmeister A. Endoscopic treatment of obesity and complications after bariatric surgery. Minerva Chir. 2017 Dec;72(6):530-537 [doi: 10.23736/S00264733.17.07466-1].

8. Schulman AR, Thompson CC. Complications of Bariatric Surgery: What You Can Expect to See in Your GI Practice. Am J Gastroenterol. 2017 Nov;112(11):1640-1655 [doi: 10.1038/ajg.2017.241. Epub 2017 Aug 15].

9. Montoya-Ramirez J, Aguilar-Espinosa F, Gutierrez-Salinas J, Blas-Azotla R, Aguilar-Soto OA. Robotassisted surgery and endoscopic management of gastrocolic fistula: A rare complication of acute pancreatitis in a patient who had undergone sleeve gastrectomy. Asian J Endosc Surg. 2018 Dec 19 [doi: 10.1111/ases.12679]. 
10. Turcu F, Balahura C, Doras I, Constantin A, Copaescu C. Symptomatic Stenosis after Laparoscopic Sleeve Gastrectomy - Incidence and Management in a High-Volume Bariatric Surgery Center. Chirurgia (Bucur). 2018 Nov-Dec; 113 (6):826-836 [doi: 10.21614/chirurgia.113.6.826].

11. Moon RC, Teixeira AF, Neto MG, Zundel N, Sander BQ, Ramos FM, Matz F, Baretta GA, de Quadros LG, Grecco E, Souza T, Barrichello SA, Filho AC, Usuy EN Jr, de Amorim AMB, Jawad MA. Efficacy of Utilizing Argon Plasma Coagulation for Weight Regain in Roux-en-Y Gastric Bypass Patients: a Multi-center Study. Obes Surg. 2018 Sep;28(9):2737-2744.

12. De Quadros LG, Neto MG, Marchesini JC, et al. Endoscopic Argon Plasma Coagulation vs. Multidisciplinary Evaluation in the Management of Weight Regain After Gastric Bypass Surgery: a Randomized Controlled Trial with SHAM Group [published correction appears in Obes Surg. 2020 Aug;30(8):32603262]. Obes Surg. 2020;30(5):1904-1916. doi:10.1007/s11695-020-04414-6.

13. De Moura DTH, Sachdev AH, Lu PW, Ribeiro IB, Thompson CC. Acute bleeding after argon plasma coagulation for weight regain after gastric bypass: A case report. World J Clin Cases. 2019;7(15):20382043. doi:10.12998/wjcc.v7.i15.2038.

14. Brunaldi VO, Farias GFA, de Rezende DT, et al. Argon plasma coagulation alone versus argon plasma coagulation plus full-thickness endoscopic suturing to treat weight regain after Roux-en-Y gastric bypass: a prospective randomized trial (with videos). Gastrointest Endosc. 2020;92(1):97107.e5. doi:10.1016/j.gie.2020.03.3757.

15. Jirapinyo P, de Moura DTH, Dong WY, Farias G, Thompson CC. Dose response for argon plasma coagulation in the treatment of weight regain after Roux-en-Y gastric bypass. Gastrointest Endosc. 2020;91(5):1078-1084. doi:10.1016/j.gie.2019.12.036.

16. Nguyen D, Dip F, Huaco JA, et al. Outcomes of revisional treatment modalities in non-complicated roux-en-Y gastric bypass patients with weight regain. Obes Surg. 2015;25(5):928-34.

17. Malik VS, Willett WC, Hu FB. Global obesity: trends, risk factors and policy implications. Nat Rev Endocrinol. 2013; 9(1):13-27.

18. Baretta GA, Alhinho HC, Matias JE, Marchesini JB, de Lima JH, Empinotti C. Argon plasma coagulation of gastrojejunal anastomosis for weight regain after gastric bypass. 2015. Obes Surg.

19. Cambi MP, Marchesini SD, Baretta GA. Post-bariatric surgery weight regain: evaluation of nutritional profile of candidate patients for endoscopic argon plasma coagulation. Arq Bras Cir Dig. 2015;28(1):403.

20. Thompson CC, Jacobsen GR, Schroder GL, Horgan S. Stoma size critical to 12-month outcomes in endoscopic suturing for gastric bypass repair. Surg Obes Relat Dis 2012; 8: 282-287.

21. De Souza LM, de Quadros LG, Kaiser RL, Campos JM, Zotarelli IJ, et al. Argon Plasma Effect about Anastomosis was Significant to Inhibit the Weight Regained in Patients Undergoing Gastric Bypass. J Obes Weight Loss Ther. 2015, 5: 264.

22. Minitab(r), Quality. Analysis. Results and the Minitab logo are registered trademarks of Minitab, Inc., in the United States and other countries. Additional trademarks of Minitab Inc. can be found at www.minitab.com. All other marks referenced remain the property of their respective owners.

23. Moberly JG, Bernards MT, Waynant KV. Key features and updates for origin 2018. J Cheminform. 2018 Feb 9;10(1):5 [doi: 10.1186/s13321-018-0259-x].

24. Schulman A, Wasif M. Abidi, Christopher C. Thompson. Plication Versus Argon Plasma Coagulation in the Treatment of Weight Regain After Gastric Bypass: A Matched Controlled Cohort Study. AGA abstracts Su1964, Mo1958,2013.

25. Heneghan HM, Yimcharoen P, Brethauer SA, Kroh M, Chand B. Influence of pouch and stoma size on weight loss after gastric bypass. Surg Obes Relat Dis. 2012 Jul-Aug;8(4):408-15.

26. Abu Dayyed BK, Acosta A, Camilleri M, Mundi MS, Rajan E, Topazian MD, Gostout CJ. Endoscopic Sleeve Gastroplasty Alters Gastric Physiology and Induces Loss of Body Weight in Obese Individuals. Clin Gastroenterol Hepatol 2015.

27. Ramos AC, Marchesini JC, de Souza Bastos EL, Ramos MG, de Souza MDG, Campos JM, Ferraz AB. The Role of Gastrojejunostomy Size on Gastric Bypass Weight Loss. Obes Surg. 2017 Sep;27(9):23172323. 
28. Galvao Neto M, Marins Campos J. Therapeutic flexible endoscopy after bariatric surgery: a solution for complex clinical scenarios. Cir Esp. 2015;93(1):1-3.

29. Schulman A, Chan WW, Thompson CC. Endoscopic suturing for failed gastric by-pass: predictors of succes. AGA, 2013, abstracts S-827 Mo1958.

30. Jiparapinyo P. et al. Evaluation of an endoscopic suturing device for transoral outlet reduction in patients with weight regain following roux en Y gastric bypass. Endoscopy 2013; 45: 532-536.

31. Jirapinyo P, Kroner PT, Thompson CC. Purse-string transoral outlet reduction (TORe) is effective at inducing weight loss and improvement in metabolic comorbidities after Roux-en-Y gastric bypass. Endoscopy. 2018;50(4):371-377. doi:10.1055/s-0043-122380.

32. Brunaldi VO, Jirapinyo P, de Moura DTH, et al. Endoscopic Treatment of Weight Regain Following Roux-en-Y Gastric Bypass: a Systematic Review and Meta-analysis. Obes Surg. 2018;28(1):266-276. doi:10.1007/s11695-017-2986-x.

Figure 1. Flow chart - Elegibility and Randomization.

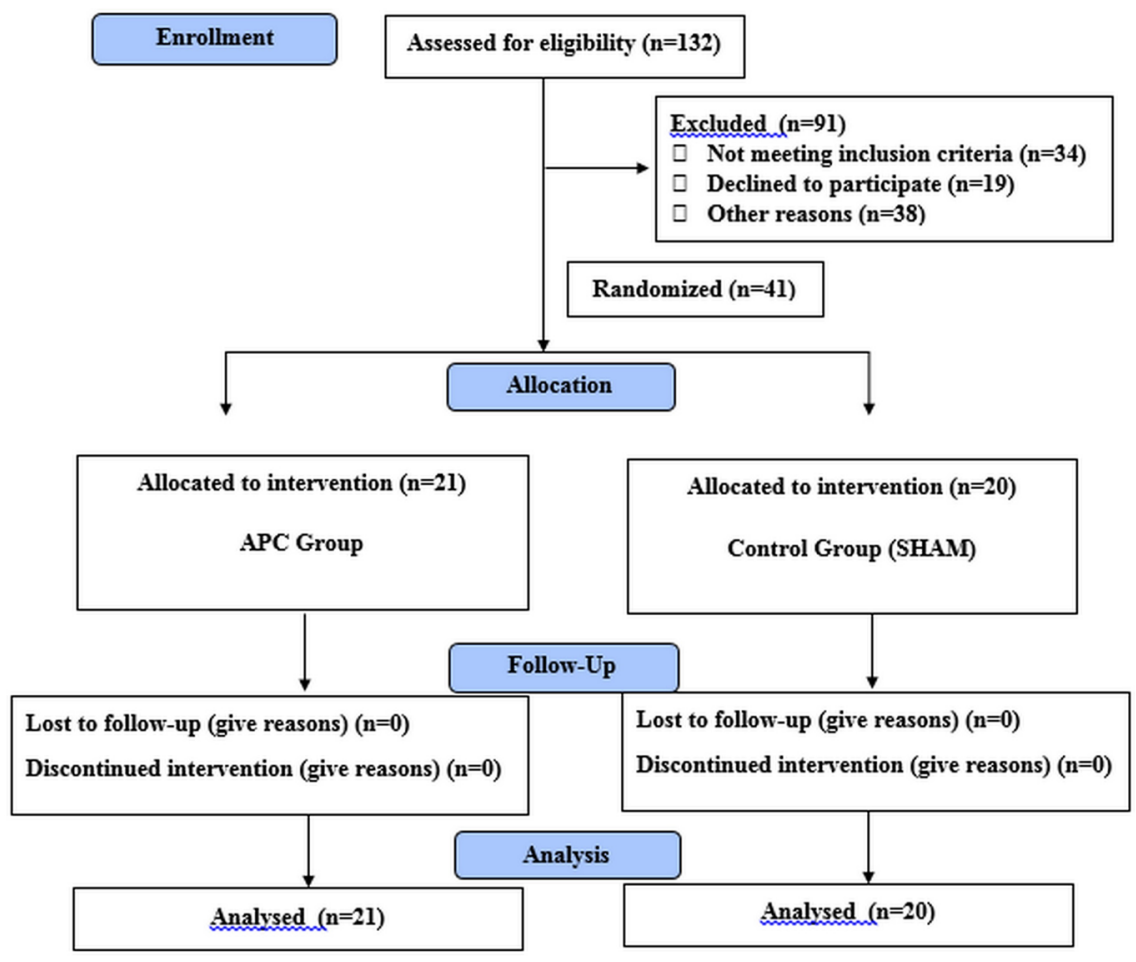

Table 1. General clinical data of weight $(\mathrm{kg})$, BMI $\left(\mathrm{kg} / \mathrm{m}^{2}\right)$, anastomotic diameter $(\mathrm{mm})$, of both APC and SHAM groups, and results of statistical comparison, with p $<0.0001$ as significant (CI 95\%).

\begin{tabular}{lll}
\hline PARAMETER & APC GROUP & SHAM GROUP \\
\hline WEIGHT (kg) & $100.04 \pm 22.27$ & $103.65 \pm 10.53$ \\
Initial & $85.02 \pm 16.05^{*}$ & $104.22 \pm 10.06$ \\
Final & $15.02 \pm 9.63^{+}$ & $-0.57 \pm 2.23$ \\
Reduction & & \\
BMI $\left(\mathrm{kg} / \mathbf{m}^{\mathbf{2}}\right)$ & & \\
Initial & $36.13 \pm 6.44$ & $36.67 \pm 2.23$
\end{tabular}




\begin{tabular}{lll}
\hline PARAMETER & APC GROUP & SHAM GROUP \\
\hline Final & $30.74 \pm 4.64^{*}$ & $36.87 \pm 2.09$ \\
Reduction & $5.38 \pm 2.21^{+}$ & $-0.21 \pm 0.39$ \\
ANASTOMOSIS & & \\
Initial & $34.25 \pm 6.13$ & $35.16 \pm 4.52$ \\
Final & $12.65 \pm 2.11^{*}$ & $35.16 \pm 4.52$ \\
Reduction & $21.60 \pm 3.19^{+}$ & 0.00 \\
\%RWL $^{+}$ & $63.95 \pm 32.08$ & $-2.65 \pm 10.24$ \\
\%TBWL $^{+}$ & $14.46 \pm 6.16$ & $-0.62 \pm 2.43$ \\
\%EWL $^{+}$ & $54.32 \pm 28.90$ & $-2.34 \pm 9.03$ \\
\hline
\end{tabular}

$+\mathrm{p}<0.0001$ between groups; ${ }^{*} \mathrm{p}<0.0001$ final versus initial.

Figure 2. Dot-Plot model chart showing the weight reduction (kg) over six months, for the APC and SHAM groups, with $95 \% \mathrm{CI}$.

\section{Weight}

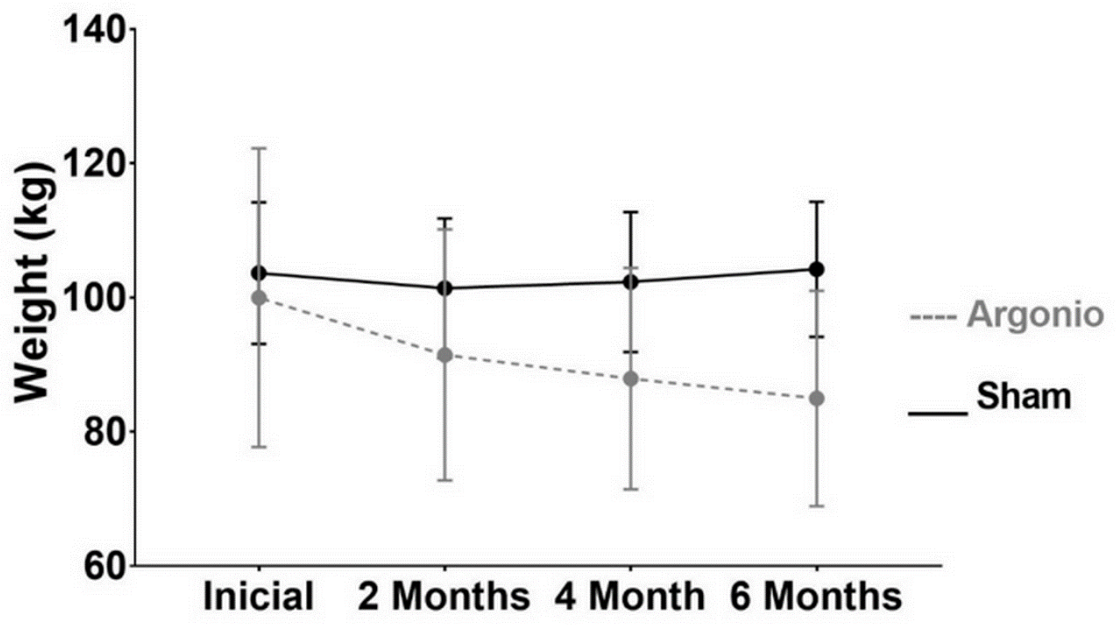

Figure 3. Box-Plot model graphs showing the values of weight and weight loss $(\mathrm{kg})$, as well as BMI $\left(\mathrm{kg} / \mathrm{m}^{2}\right)$ in relation to the APC and SHAM groups, with $\mathrm{p}<0.0001$ as significant (CI 95\%). 


\section{Weight Loss}

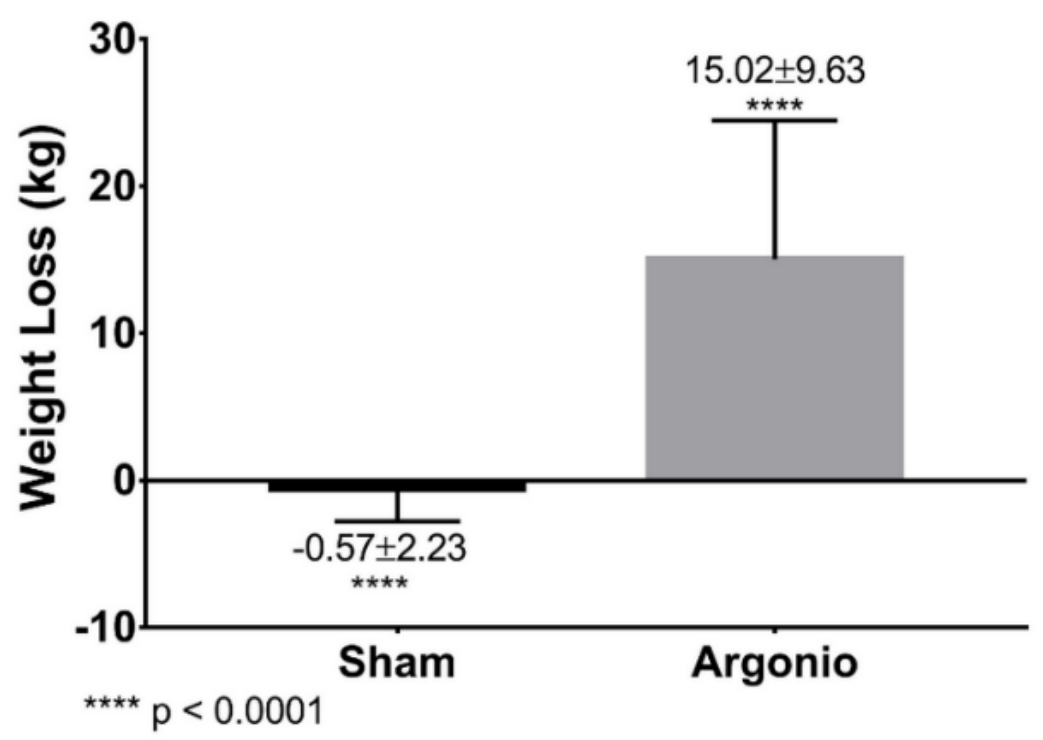

Weight (Sham)

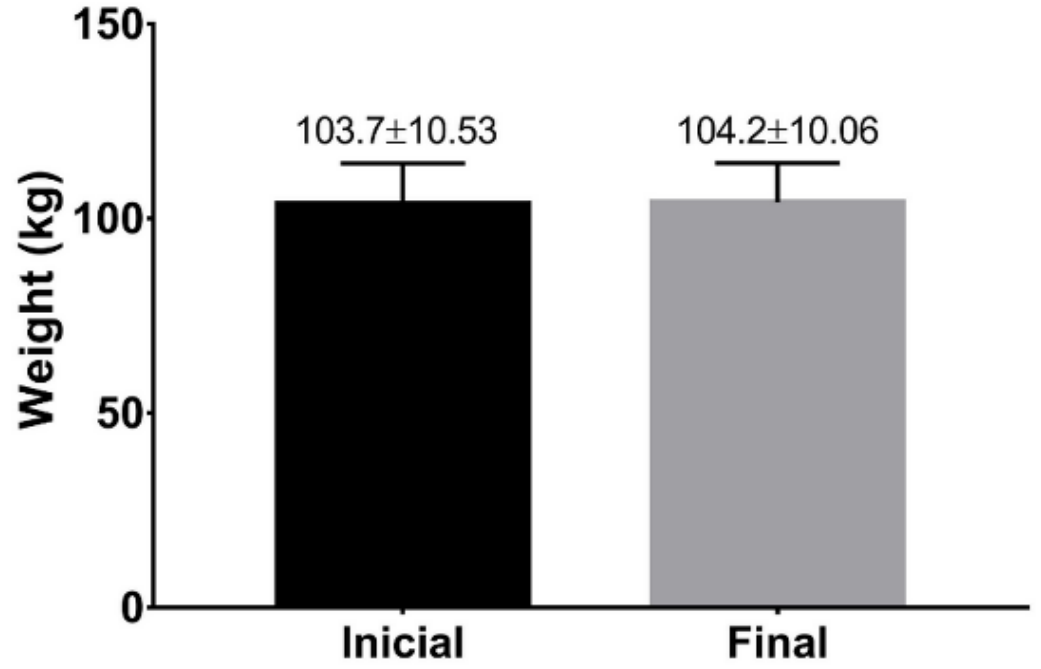


Weight (Argonio)

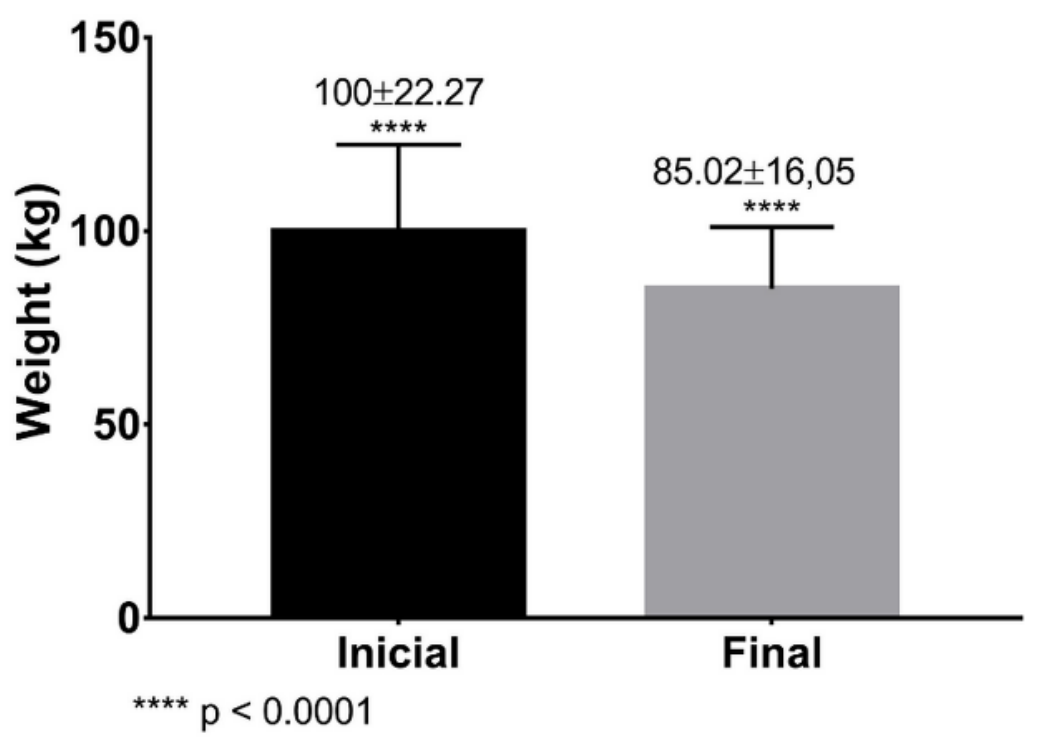

BMI (Sham)

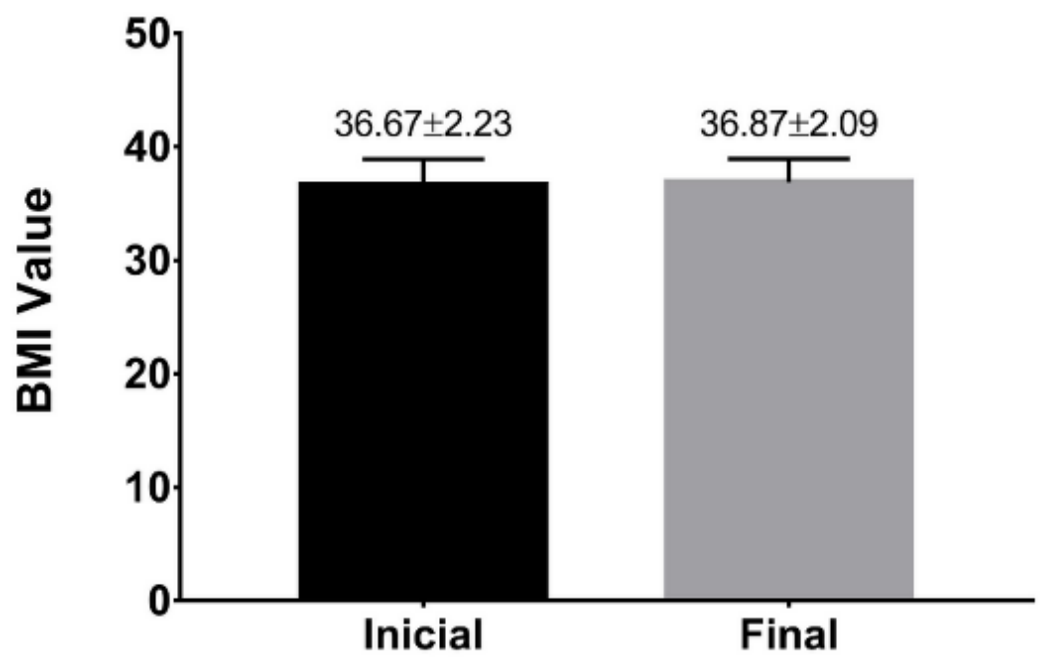




\section{BMI (Argonio)}

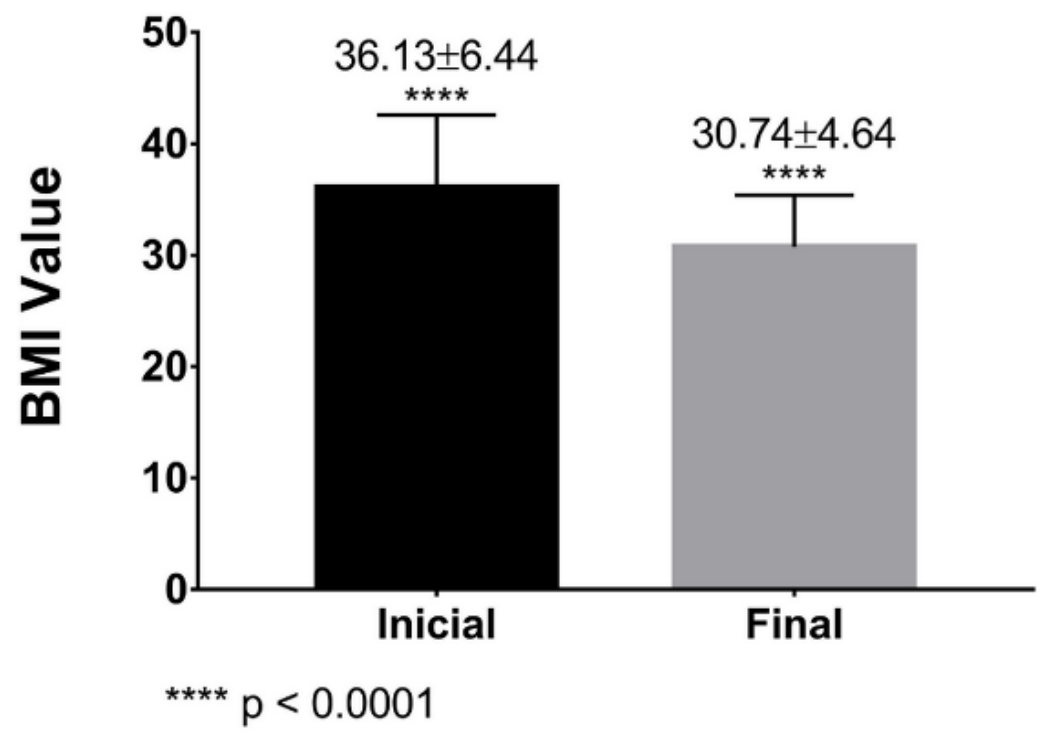

Figure 4. Box-Plot model graphics showing the values in percentage of weight regained total body weight loss and excess weight loss in relation to the APC and SHAM groups, with p <0.0001 as significant (CI $95 \%)$.

\section{$\%$ Regained Weight}

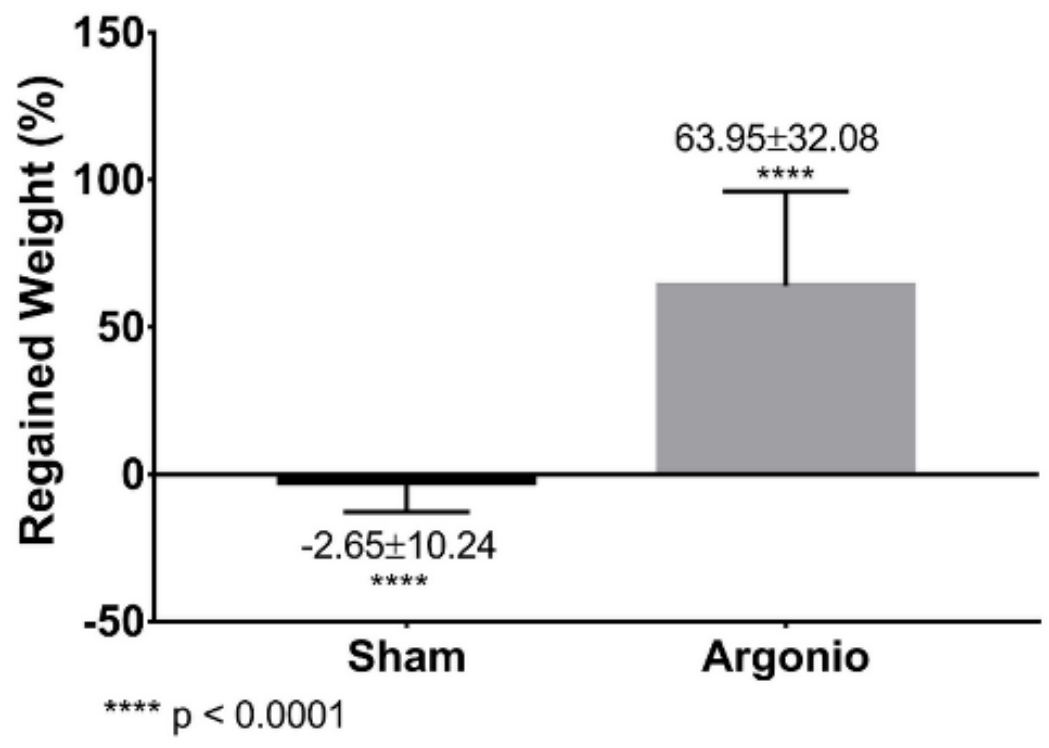




\section{$\%$ TBWL}

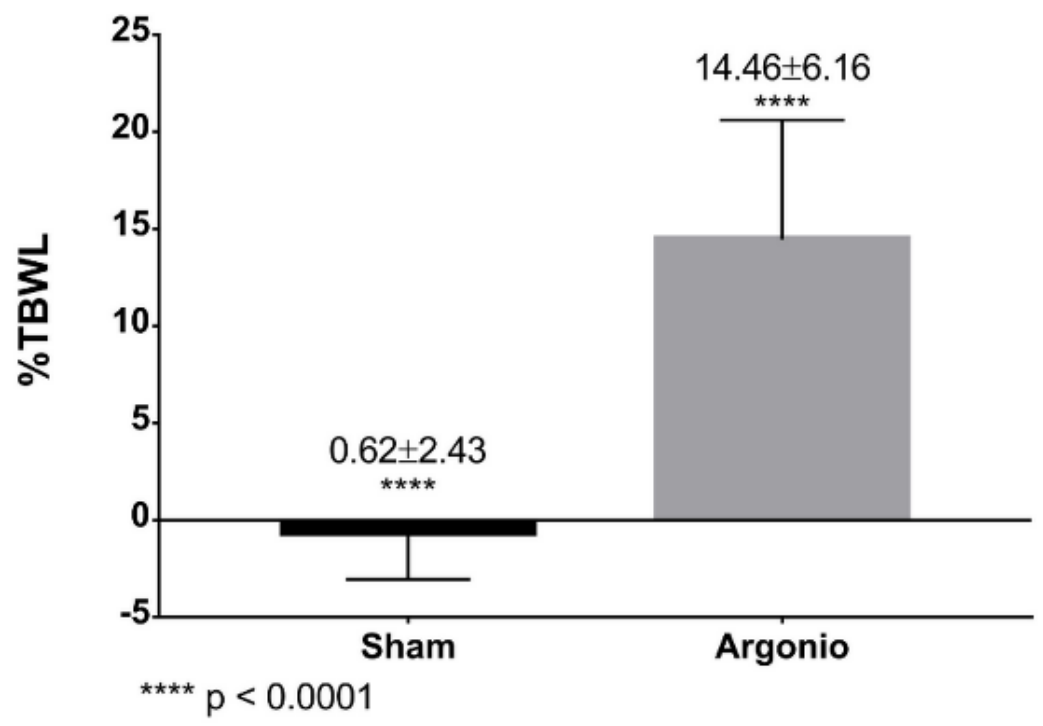

$\%$ EWL

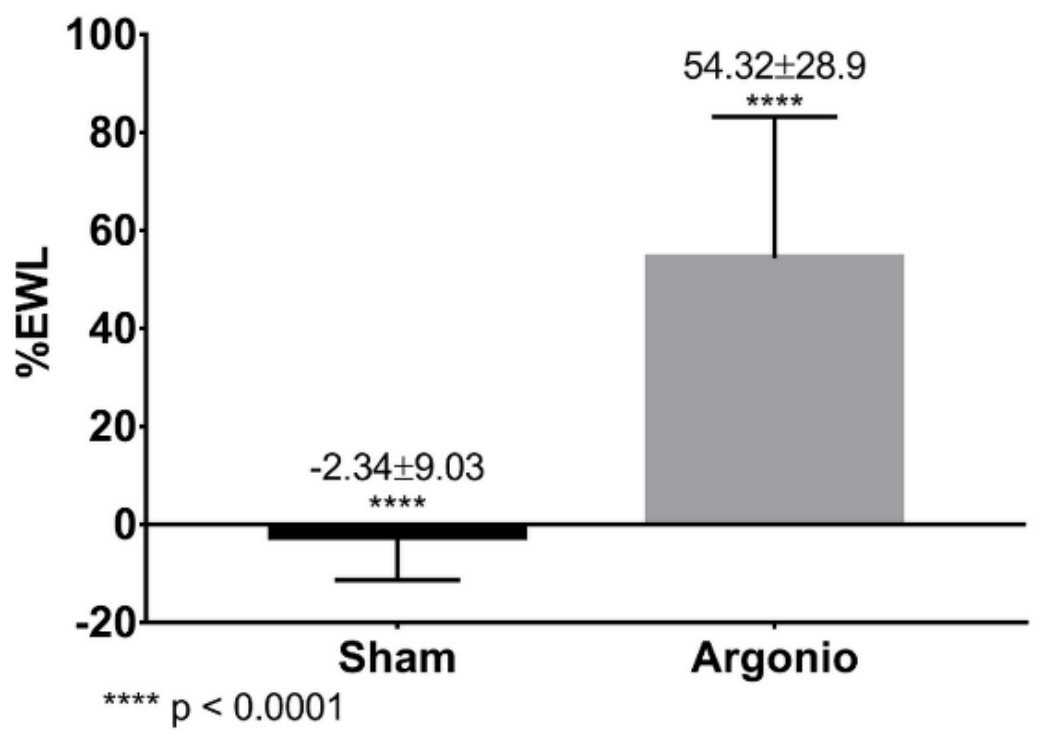

Figure 5. Box-Plot model graph showing the values of the decrease in the diameter of the gastrojejunal anastomosis to the APC group, with $\mathrm{p}<0.0001$ as significant (CI 95\%). 


\section{Anastomosis (Argonio)}

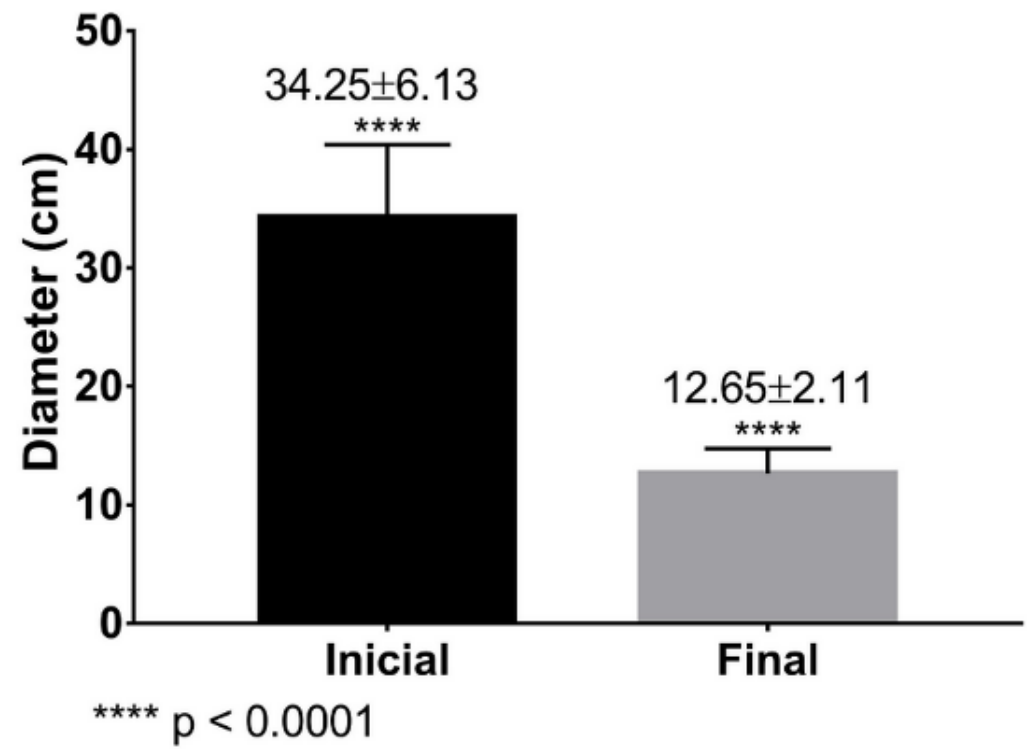

Figure 6. Box-Plot model graphs showing the values of glycosylated hemoglobin (HbA1c) in percentage and triglycerides ( $\mathrm{mg} / \mathrm{dL}$ ) to the APC groups, with $\mathrm{p}<0.0001$ as significant (CI 95\%).

HbA1c (Argonio)

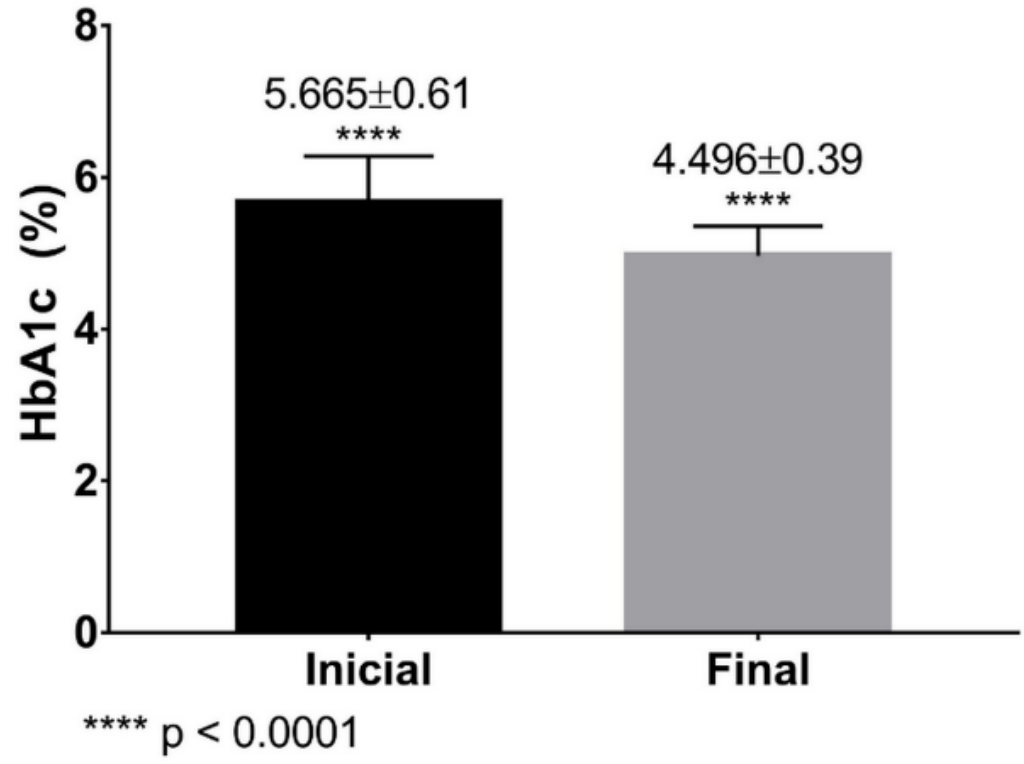




\section{Triglycerides (Argonio)}

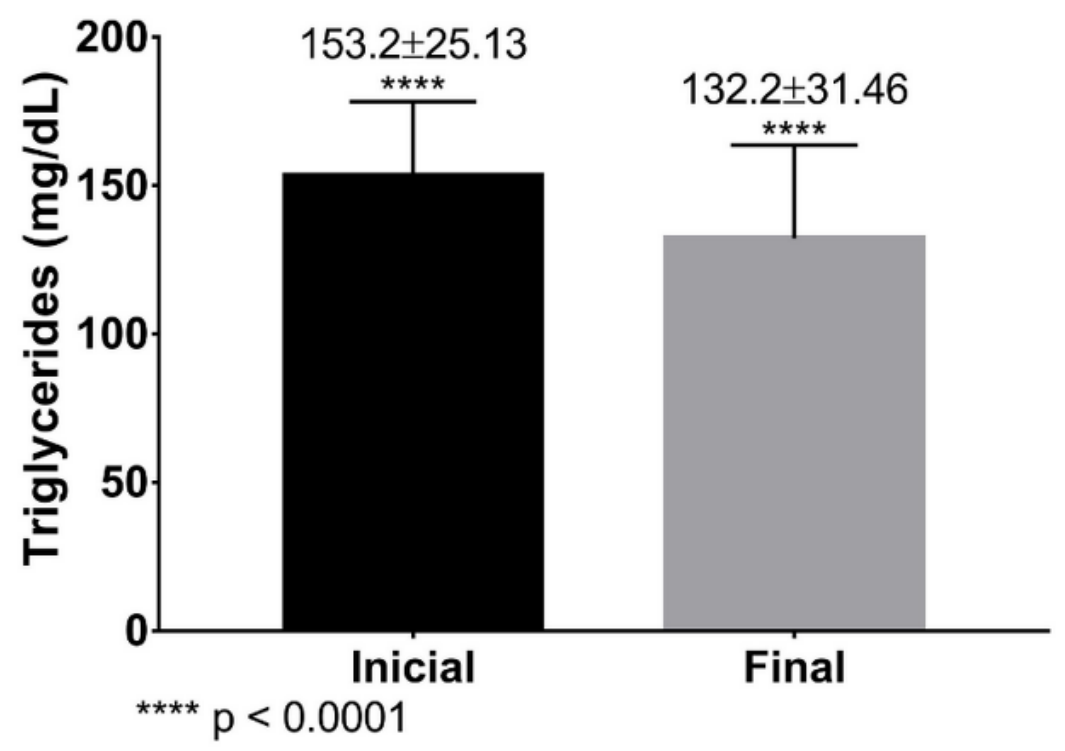

Figure 7. GJA diameter images at 2, 4, and 6 months after APC application. 


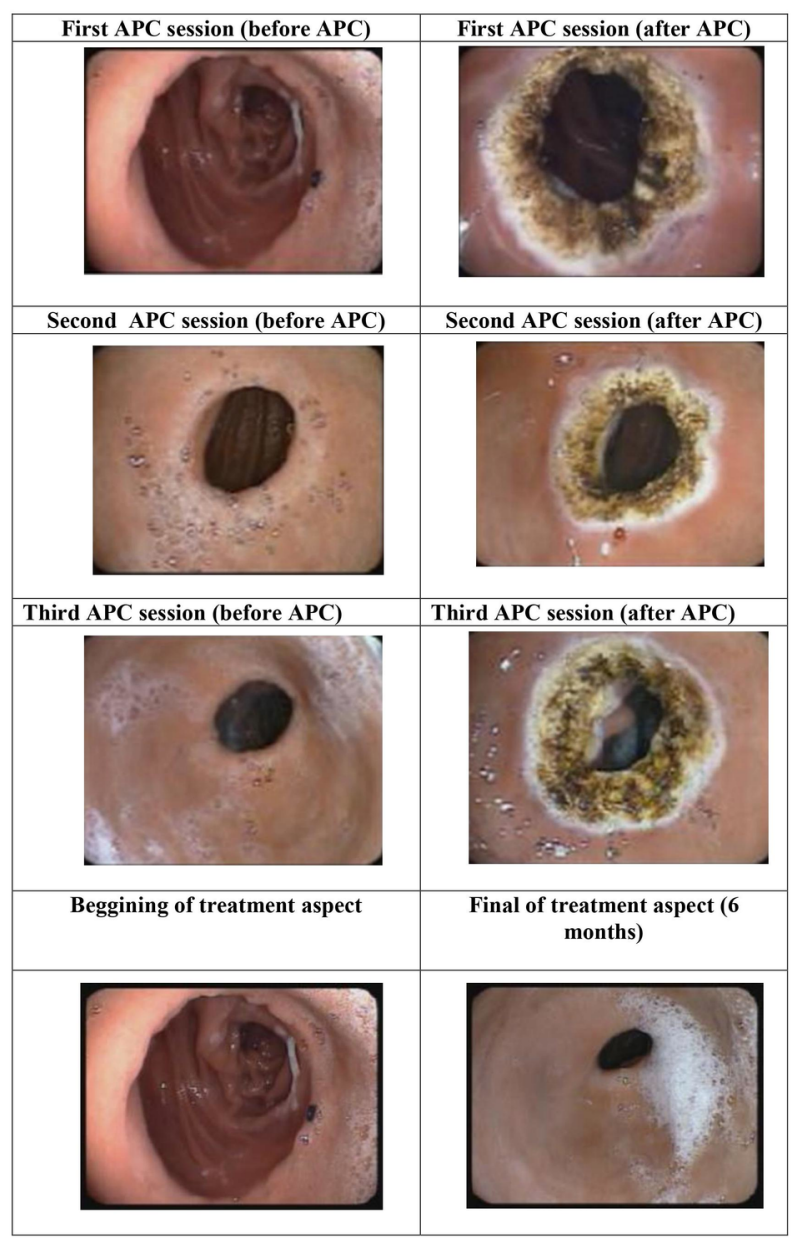

$\overline{\text { Argon Application - } 2 \text { MONTHS }}$ Result - 2 MONTHS

Argon Application - 4 MONTHS Result - 4 MONTHS

Argon Application - 6 MONTHS Result - 6 MONTHS 